\title{
Relation between use of health check ups starting in middle age and demand for inpatient care by elderly people in Japan
}

\author{
Kozo Tatara, Fumiaki Shinsho, Masatake Suzuki, Toshio Takatorige, Noriyuki Nakanishi, \\ Kenji Kuroda
}

\begin{abstract}
Objective - To find out whether there is any correlation between the use of general health check ups (provided for by the Health Services for the Elderly Act 1982) by insured Japanese residents aged 40 or older and demand by the elderly for inpatient care.

Design-A questionnaire was posted in 1988 to municipal offices of Japanese cities. All questionnaires were returned with data for 1983 and 1986 .
\end{abstract}

Setting-All 509 Japanese cities with a population of 30 000-199999.

Subjects-All people aged 40 or older who hold a resident card and are not offered health examinations at work are eligible for general health check ups. The questionnaire also inquired about use of inpatient care by elderly residents (aged 70 or older) who were covered by national health insurance.

Main outcome measures-Correlation coefficients between the rates of use of general health check ups and mean annual bed days for the elderly. Comparison of relative changes by analysis of correlation between improvement indices in mean bed days and mean inpatient fee.

Results - In cities with relatively high rates of use of health check ups both the mean annual bed days and the mean inpatient fee for the elderly tended to be low. Correlation coefficients between the logarithmic rates of use of check ups and mean bed days by sizes of cities and number of beds were al negative values. There tended to be more correlation between improvement indices for rate of use of check ups and both mean bed days and mean inpatient fee with higher rates of use in 1983, and the correlation was significant for rates of $60 \%$ or more.

Conclusions-Strong health service programmes that start in middle age decrease the demand for inpatient care of the elderly. It was estimated that in a single year from 1985 to 1986 , when there was an increase in the rate of use of check ups from $25 \cdot 5 \%$ to $\mathbf{2 7 . 6 \%}$, the reduction in the number of bed days for the total of 8.5 million elderly insured people was $2 \cdot 21$ million bed days.

\section{Introduction}

The Health Services for the Elderly Act 1982 has provided for six health services that are inexpensive or free for all people in any area of Japan who hold a resident card, are at least 40 years old, and are not offered periodical health examinations at their place of work. These services comprise a notebook given to residents, in which they can keep the results of health check ups; health education for groups; health counselling for individuals; health examinations, including general health check ups, with special examinations when indicated, and screening for gastric and cervical cancer; rehabilitation programmes; and home visits. These services have come to be widely used in the past few years.' The act is a key part of governmental efforts to prepare for the rapid increase in the absolute and relative numbers of elderly people projected for the near future.

Middle aged people are covered in this act, which was drawn up for the elderly (aged 70 or older), because it is generally believed that maintenance of health in middle aged people will contribute to health when these people become elderly. ${ }^{2}$

The numbers of people who received general health check ups in 1983, the first full year for which the act was in effect, and 1986, the end of the first five year period for the act (counting 1982), were $6 \cdot 17$ million and 8.13 million, respectively, among whom 0.94 million and 1.23 million people were hypertensive according to the World Health Organisation definition. ${ }^{3}$ In 1983 and $1986,2.00$ million and 3.68 million people, respectively, received special examinations.

In this paper "general health check ups" refers to examinations provided directly by local health authorities or by contracted local physicians as a result of the act of 1982; it includes general physical examinations by doctors, measurement of blood pressure, and urine analysis, all of which are done for all residents aged 40 or older who request a health check up. Assays of red blood cell count, haemoglobin concentration, packed cell volume, total serum cholesterol concentration, blood glucose concentration, and aspartate aminotransferase and alanine aminotransferase activities; electrocardiography; and an eye examination are also done in special examinations if indicated. Residents can usually obtain general health check ups at community health centres or doctors' surgeries. The dates when the health examination services are available are announced in newsletters published periodically by the local governments. After the check ups, depending on the results, the residents can receive health education in a group setting or ask for individual health counselling. When necessary a public health nurse may visit the resident to offer information.

In this survey we looked for correlation between the rate of use of general health check ups provided for by the act in 509 Japanese cities and the use of inpatient services by people aged 70 or older in these cities.

\section{Methods}

A questionnaire was posted in March 1988 to the municipal offices of all 509 cities in Japan with a population of 30000-199999 on 31 March 1987, according to the resident card records of each city. The six districts in Tokyo of appropriate size (out of the total of 23 districts) were included and counted as six cities.

The municipal officials assigned to the task of completing the questionnaire were the people with 
main responsibility for carrying out and promoting health services in each city. Data on health examination services were managed by the same officials; data on the use of inpatient care were managed by the department of national health insurance of the city but provided by the same officials as before.

All of the officials responded with data for 1983 and 1986. Four replies were excluded because of incomplete information about the numbers of people receiving the general health check ups. In addition to information about the rate (percentage) of eligible persons who received the check ups the questionnaire inquired about the use of inpatient care by residents aged 70 or older covered by national health insurance (in most cities this was about two thirds of the population of this age). In this study the mean number of annual bed days (mean bed days) refers to the mean length of time spent as a hospital inpatient per insured elderly person covered by national health insurance. The mean annual inpatient medical fee (mean inpatient fee) is the mean annual payment by insurance for time spent in hospital per insured person in this age group. Among 505 replies, 19 gave incomplete information concerning mean bed days and 13 gave incomplete information concerning the mean inpatient fee.

To compare relative changes rather than absolute ones we calculated correlation coefficients between improvement indices in the various items studied as the ratio of change from 1983 to 1986 multiplied by either the rate of achievement of the target set by the government or the ratio of the mean for a particular city divided by the mean for the entire country. The improvement index for the rate of use of general health

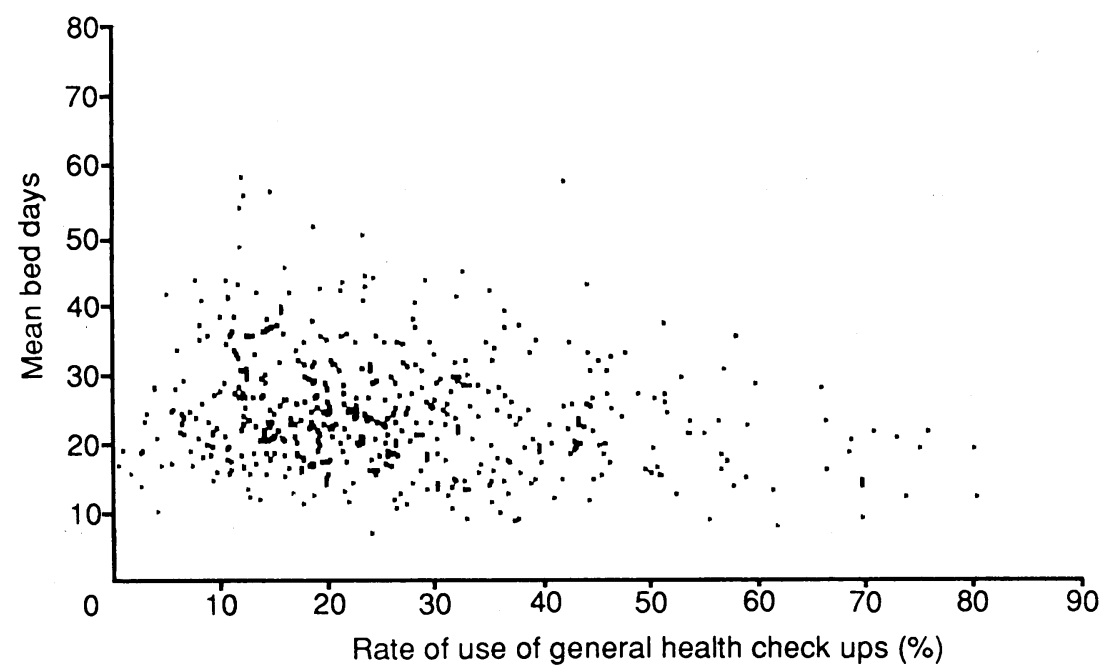

FIG 1-Scattergram of mean bed days for the elderly $v$ rate of use of general health check ups by middle aged and older people for fapanese cities with population 30000-199 $999(n=486)$

.

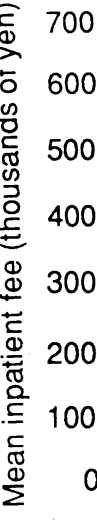

0

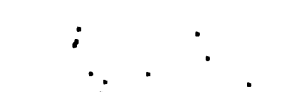

$\because \because \because \because:-\because \quad: \quad \therefore$

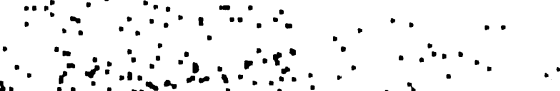

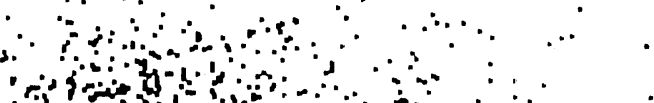

10 check ups in each city was calculated as the rate of use of check ups in 1986/the rate of use of check ups in 1983 multiplied by the rate of use of check ups in 1986/the national target for rate of use of check ups in 1986 $(50 \%)$, all multiplied by 100 . The mean (standard deviation) improvement index (number of cities $=339$ ) when all results for rates of less than $10 \%$ for 1983 were excluded was $92 \cdot 2(73 \cdot 1)$.

The improvement index for the mean bed days in each city was calculated as the mean bed days in 1986/ the mean bed days in 1983 multiplied by the mean bed days in 1986/the mean bed days for all cities surveyed in 1986 (20.9 days), all multiplied by 100 . In these and all other calculations of overall means differences in the sizes of the cities were ignored. The mean (SD) improvement index (number of cities=457) was 111.9 $(44 \cdot 5)$.

The improvement index for the mean inpatient fee of each city was calculated as the mean inpatient fee in 1986/mean inpatient fee in 1983 multiplied by the mean inpatient fee in 1986/mean inpatient fee for all cities surveyed in 1986 (273000 yen), all multiplied by 100. The mean (SD) improvement index (number of cities $=486)$ was $122 \cdot 1(41 \cdot 6)$. For mean bed days and the mean inpatient fee a low improvement index reflected improvement (less time in hospital and lower medical fees). In preliminary calculations the rate of use of health check ups, mean bed days, and the improvement indices for the rate of use of check ups were found to have skewed distributions, so we converted these variables to logarithmic values before the regression analysis.

Table I shows the number of cities, number of eligible people, and size of the population aged 40 or older classified according to rate of use of general health check ups in a total of 505 cities in 1986. Eligible people included all people aged 40 or older who were insured by national health insurance $(59 \cdot 4 \%$ of the age group).

TABLE I-Numbers of cities, people eligible for general health check ups, and population aged $\geqslant 40$ according to rate of use of check ups ${ }^{\star}$ in 1986

\begin{tabular}{lccc}
\hline & No of cities & $\begin{array}{c}\text { No of eligible } \\
\text { people } \\
\text { (thousands) }\end{array}$ & $\begin{array}{c}\text { Population } \\
\text { aged } \geqslant 40 \\
\text { (thousands) }\end{array}$ \\
\hline$<10 \%$ & 50 & 1131 & 1719 \\
$10-20 \%$ & 153 & 2902 & 4943 \\
$20-30 \%$ & 130 & 2154 & 3717 \\
$30-40 \%$ & 82 & 1501 & 2524 \\
$40-50 \%$ & 44 & 592 & 1027 \\
$50-60 \%$ & 27 & 411 & 701 \\
$\geqslant 60 \%$ & 19 & 214 & 354 \\
\hline Total (mean rate 26.5\%) & 505 & 8905 & 14985
\end{tabular}

^Provided by the Health Services for the Elderly Act 1982. tThe lower number of ranges is included, the upper is not.

\section{Results}

In cities with relatively high rates of use of general health check ups both the mean bed days and the mean inpatient fee tended to be low in 1986 (figs 1 and 2). The mean (SD) bed days and inpatient fee were 20.9 (8.7) days (486 cities) and $273000(89000)$ yen (492 cities) respectively; when the rate of use was $50 \%$ or more these values were $17 \cdot 0(6 \cdot 7)$ days ( 45 cities) and 228000 (67 000) yen (44 cities).

Rates of use of check ups and mean bed days-The correlation coefficient between logarithmic rates of use of check ups and mean bed days for cities where the rate of use was $10 \%$ or more was $-0.210(p<0.01)$ in 1986 , and the equation for the line of regression was $\mathrm{Y}=3.53-0 \cdot 174 \mathrm{X}$, where $\mathrm{Y}$ is logarithmic bed days and $\mathrm{X}$ is the logarithmic rate of use (table II). The rate of use of health check ups was somewhat smaller in larger cities. The correlation coefficients were negative values 
in cities of all sizes. The coefficient with the largest absolute value was -0.398 for cities with a population of from 80000 to 99999 . The correlation between health check ups and hospital use was quite consistent in that it was negative in all categories of number of beds per unit population (data not shown).

TABLE II-Correlation coefficients between rate of use of general health check ups ${ }^{\star}$ by middle aged and older people and mean-annual bed days per insured elderly person in 1986, both expressed logarithmically, in cities classified by size

\begin{tabular}{|c|c|c|c|c|c|}
\hline \multirow[b]{2}{*}{$\begin{array}{l}\text { Population } \dagger \\
\text { (thousands) }\end{array}$} & \multirow[b]{2}{*}{$\begin{array}{l}\text { No of } \\
\text { cities } \neq\end{array}$} & \multirow[b]{2}{*}{$\begin{array}{l}\text { Mean rate } \\
\text { of use }\end{array}$} & \multirow[b]{2}{*}{$\begin{array}{l}\text { Correlation } \\
\text { coefficient }\end{array}$} & \multicolumn{2}{|c|}{$\begin{array}{l}\text { Line of regression } \\
\qquad \mathrm{Y}=\mathrm{a}+\mathrm{bX}\end{array}$} \\
\hline & & & & a & b \\
\hline $30-40$ & 92 & $34 \cdot 3 \%$ & -0.175 & $3 \cdot 48$ & $-0 \cdot 158$ \\
\hline $40-50$ & 71 & $33 \cdot 0 \%$ & $-0.296 ₫$ & 3.74 & $-0 \cdot 238$ \\
\hline $50-60$ & 69 & $30 \cdot 1 \%$ & $-0 \cdot 100$ & $3 \cdot 28$ & $-0 \cdot 101$ \\
\hline $60-70$ & 48 & $25 \cdot 7 \%$ & -0.131 & $3 \cdot 39$ & $-0 \cdot 101$ \\
\hline $70-80$ & 33 & $24 \cdot 4 \%$ & $-0 \cdot 257$ & $3 \cdot 70$ & -0.253 \\
\hline $80-100$ & 39 & $22 \cdot 2 \%$ & -0.3980 & $4 \cdot 00$ & $-0 \cdot 361$ \\
\hline $100-200$ & 87 & $25 \cdot 2 \%$ & $-0 \cdot 224 \oint$ & 3.52 & $-0 \cdot 165$ \\
\hline Total & 439 & $28 \cdot 9 \%$ & $-0 \cdot 210$ & $3 \cdot 53$ & $-0 \cdot 174$ \\
\hline
\end{tabular}

$\mathrm{Y}=$ mean annual bed days per insured elderly person, expressed logarithmically; $\mathrm{X}=$ rate $(\%)$ of use of general health check ups by eligible people, expressed logarithmically.

$\star$ Provided by the Health Services for the Elderly Act 1982.

tThe lower number of ranges is included, the upper is not.

$\neq$ Cities where the rate of use of general health check ups was under $10 \%$ are excluded.

@ $<<0 \cdot 05, \| p<0 \cdot 01$.

Correlation of improvement indices - The correlation coefficients between the logarithmic improvement indices in the rate of use of check ups and mean bed days and between the improvement indices for rate of use of check ups and the mean inpatient fee were negative values in cities classified by their rates of use of check ups in 1983 (table III). There tended to be more correlation for higher rates of use in 1983. Where this rate was $60 \%$ or greater the correlation coefficient for the rate of use and mean bed days was -0.553 $(\mathrm{p}<0.05)$.

TABLE III-Correlation coefficients between improvement indices for rate of use of general health check ups ${ }^{\star}$ by middle aged and older people, expressed logarithmically, and those for mean bed days $\left(r^{i}\right)$ and mean inpatient fee $\left(r^{2}\right)$ for the elderly in 1986 for different rates of use of general health check ups in 1983

\begin{tabular}{|c|c|c|}
\hline Rate of use in 1983 & $\begin{array}{l}\text { Mean bed days } \\
\qquad\left(\mathbf{r}^{1}\right)\end{array}$ & $\underset{\left(\mathbf{r}^{2}\right)}{\text { Mean inpatient fee }}$ \\
\hline $\begin{array}{l}\geqslant 10 \% \\
\geqslant 20 \% \\
\geqslant 30 \% \\
\geqslant 40 \% \\
\geqslant 50 \% \\
\geqslant 60 \% \\
\geqslant 70 \%\end{array}$ & $\begin{array}{l}-0 \cdot 089(n=313) \\
-0 \cdot 100(n=164) \\
-0 \cdot 073(n=94) \\
-0 \cdot 192(n=50) \\
-0 \cdot 251(n=27) \\
-0.553+(n=14) \\
-0.592(n=9)\end{array}$ & $\begin{array}{l}-0 \cdot 144+(n=326) \\
-0 \cdot 129(n=168) \\
-0.151(n=95) \\
-0.211(n=50) \\
-0.317(n=27) \\
-0.441(n=14) \\
-0.525(n=8)\end{array}$ \\
\hline
\end{tabular}

Rates of use of general health check ups and cancer screening tests-Correlation coefficients between logarithmic rates of use of general health check ups and both screening for gastric cancer and screening for cervical cancer were all positive and significant (table IV).

\section{Discussion}

Promoting Better Health ${ }^{4}$ recommends that health checks for older patients be provided as a part of primary care. Roworth states that "evidence from large randomized controlled trials in the USA and the UK suggests that multiphasic screening is of no benefit." He therefore concludes that "there is an ethical obligation on the part of those who advocate screening in old age to show that it is beneficial." In Japan, even though such evidence was incomplete, the government started
TABLE IV-Correlation coefficients between rates of use of general health check ups ${ }^{\star}$ and screening for gastric cancer $\left(r^{*}\right)$ and for cervical cancer $\left(r^{\top}\right)$, all expressed logarithmically, in 1986 in cities classified by size

\begin{tabular}{llc}
\hline $\begin{array}{l}\text { Population } \dagger \\
\text { (thousands) }\end{array}$ & $\begin{array}{c}\text { Screening for } \\
\text { gastric cancer } \\
\left(\mathbf{r}^{3}\right)\end{array}$ & $\begin{array}{c}\text { Screening for } \\
\text { cervical cancer } \\
\left(\mathrm{r}^{3}\right)\end{array}$ \\
\hline $30-50$ & $0 \cdot 458 \ddagger(\mathrm{n}=174)$ & $0 \cdot 407 \ddagger(\mathrm{n}=174)$ \\
$50-100$ & $0 \cdot 512 \ddagger(\mathrm{n}=223)$ & $0 \cdot 434 \ddagger(\mathrm{n}=223)$ \\
$100-200$ & $0 \cdot 539 \ddagger(\mathrm{n}=107)$ & $0 \cdot 356 \ddagger(\mathrm{n}=107)$ \\
\hline Total & $0 \cdot 530 \ddagger(\mathrm{n}=504)$ & $0 \cdot 426 \ddagger(\mathrm{n}=504)$
\end{tabular}

$\mathrm{n}=$ Number of cities

^Provided by the Health Services for the Elderly Act 1982. tThe lower number of ranges is included, the upper is not. $\ddagger \mathrm{p}<0 \cdot 01$.

to provide health check ups in 1983, in part because of a long tradition of offering local health services. ${ }^{6}$ Thus the results we examine here are of services that have been available for a number of years, especially in those cities in which a rate of use of $60 \%$ or more had already been reached in 1983. In 1988 the number of people who received general health check ups in Japan was 8654180 . The nationwide rate of eligible people aged 40 or older receiving the check ups was $30 \cdot 7 \%$. In that year, 3729591 people were screened for gastric cancer in local health programmes and 3715572 women (aged 30 or older) were screened for cervical cancer. ${ }^{3}$ As Marmot and Smith write, "it will be important to determine whether this [practice in Japan] makes a further contribution to the reduction of mortality."

In our study we have analysed the effects of these health services, with the percentages of people who received a general health check up as the main index. A negative relation between the rate of use of health check ups and hospital use in the elderly was found consistently in cities of different sizes when results for rates of less than $10 \%$ were excluded, and an association between an increased use of check ups and reduced use of hospital inpatient services was found in cities that had high rates of use of health check ups. In cities that strongly promoted health services programmes that start in middle age the decrease in the demand by the elderly for inpatient medical care might be to some extent the result of use of these services.

Our results suggest that the rate of use of general health check ups is a useful index of the general standard of health services in Japanese cities. Some correlation was found between logarithmic rates of use of the check ups and both screening for gastric cancer and screening for cervical cancer, although these services are not necessarily provided at the same time or place.

The number of elderly people aged 70 or older insured by the national health insurance and the total number of the elderly insured by any insurance programme were about 5.6 million and 8.5 million respectively in 1986, and the nationwide rate of use of general health check ups increased from $25.5 \%$ in 1985 to $27 \cdot 6 \%$ in 1986 . $^{3}$ Calculation from the corresponding regression line showed that the mean $(95 \%$ confidence interval) bed days per elderly person insured by the national health insurance in 1985 and 1986 were 19.42 $(18.89$ to 19.97$)$ and $19 \cdot 16(18.64$ to $19 \cdot 70)$ respectively. The reduction in mean bed days per elderly person between these years was 0.26 bed days. For all elderly people insured by the national health insurance we estimate that the reduction was 1.46 million bed days; for the total number of the elderly insured by any insurance this figure was about 2.21 million bed days.

This study was supported in part by grants from the Japan Health Promotion and Fitness Foundation. We thank the 
Department of Health Services for the Elderly, Ministry of Health and Welfare, for promotion of this study.

1 Department of Health Services for the Elderly, Ministry of Health and Welfare. Rojin hoken jigyo no susumekata: toshibu ni okeru torikumi. Tokyo: Gyosei, 1990.

2 Breslow L. Prospects for improving health through reducing risk factors. Prev Med 1978;7:449-58.

3 Kosei Tokei Kyokai. Kokumin eisei no doko, 1990. Tokyo: Kosei Tokei Kyokai, 1990.
4 Secretaries of State for Social Services, Wales, Northern Ireland, and Scotland. Promoting better health. The government's programme for improving priman Promoting better health. The gover
health care. London: HMSO, 1987.

5 Roworth MA. Screening in the elderly. Public Health 1989;103:377-83

6 Tatara K, Shinsho F, Asakura S, Hashimoto M, eds. Shi-cho-son no hoken jigvo. Tokyo: Nihon Koshueisei Kyokai, 1984

7 Marmot MG, Smith GD. Why are the Japanese living longer? BMf 1989;299: $1547-51$.

(Accepted 21 fanuary 1991)
Combined Breast Clinic, St George's Hospital, London SW17 0QT A Yelland, $\mathrm{MB}$, research registrar

M D Graham, FRCs, research registrar

P A Trott, FRCPATH, consultant pathologist

H T Ford, FRCR, consultant radiotherapist

R C Coombes, FRCP, consultant oncologist

J-C Gazet, FRCS, consultant surgeon

N G Polson, PHD, statistician

Correspondence to:

Mr Gazet.

BMf 1991;302:618-20

\title{
Diagnosing breast carcinoma in young women
}

\author{
A Yelland, M D Graham, P A Trott, H T Ford, R C Coombes, J-C Gazet, N G Polson
}

\begin{abstract}
Objective-To assess the individual and combined diagnostic accuracy of clinical examination, mammography, and fine needle aspiration biopsy in young women with breast cancer.

Design-Analysis based on case notes of patients presenting with breast cancer during 1971-89.

Setting-A combined breast clinic.

Patients-Consecutive series of 81 women aged $<36$ with histologically proved breast cancer presenting with a discrete mass over 19 years.

Main outcome measures-Results of clinical examination, xeromammography or conventional mammography, fine needle aspiration biopsy, and examination of tissue removed by surgery.

Results - The clinical diagnosis was correct in $\mathbf{4 7}$ women and radiography in 35 . Fine needle aspiration biopsy was correct in 47 of the 63 women in whom it was successfully performed. Fine needle aspiration was significantly more accurate than mammography $(78 \% v 45 \%, \mathrm{p}<0.01)$. Ten $(16 \%)$ patients had negative results on clinical examination, mammography, and fine needle aspiration.

Conclusion-Mammography alone seems inadequately sensitive to detect breast cancer in young patients. When all investigations give negative results excision biopsy is the only way of obtaining a definitive diagnosis.
\end{abstract}

\section{Introduction}

Mortality from breast cancer has not changed over the past 30 years. Accurate early diagnosis is needed to improve quality of life and reduce mortality as prognosis depends on tumour size at presentation. This is the basis of the national screening programme.

A particularly emotive problem is the diagnosis of carcinoma of the breast in young women. About two thirds of patients presenting to breast clinics are younger than 36; most have benign disease, but roughly $3 \%$ of all carcinomas occur in this age group. Clinical examination, mammography, and fine needle aspiration biopsy are thought to be necessary for diagnosis.' To determine whether this is true we reviewed the methods used to diagnose cancer in patients presenting to our clinic over 19 years.

\section{Patients and methods}

We reviewed a consecutive series of 2820 women with known breast carcinoma presenting between 1971 and 1989 . We found 81 women aged less than 36 with carcinoma proved by histopathological evaluation of a biopsy specimen. Specimens were embedded in paraffin wax and multiple sections stained with haematoxylin and eosin. A consultant histopathologist examined the sections.
All the women presented with a discrete lump in the breast. They were examined by a consultant in our clinic and the clinical diagnosis was recorded as benign or malignant. The general practitioner's diagnosis was also noted. Seventy seven women had mammography. The 62 women seen before October 1986 had xeromammography and the other 15 had standard mammography with a Senograph 500T (IGE, Slough, United Kingdom) machine.

Biopsy specimens were obtained by fine needle aspiration in 67 patients. The technique was always performed by a consultant and in a standard manner. The slides were examined by a consultant pathologist. The service became available in 1975; 11 patients presented before this, and three presented subsequently but did not have a fine needle aspiration biopsy.

Other details noted were: family history of breast disease, either benign or malignant; use of the contraceptive pill for longer than six months; oestrogen receptor status, a value less than $15 \mathrm{fmol} / \mathrm{mg}$ of cytosol being considered a negative result; histological type of carcinoma; and clinical size of the tumour at presentation.

The data obtained were subjected to a standard binomial test by an independent statistician.

Eighty one randomly selected women who were matched for age and had had benign breast disease (fibroadenoma, fibrocystic disease, duct ectasia, and normal tissue) during the same period where used as controls.

\section{Results}

Of the women aged less than 36 with malignant disease, 61 were aged 31-35 (table I), and the median age at presentation was 33 . Nine women had a first degree relative who had had malignant breast disease and eight had a relative who had had benign disease. Among the control group, a relative had had malignant disease in eight and benign disease in 13 .

Fifty three women in both groups had taken the contraceptive pill for longer than six months. The oestrogen receptor status was negative in 32 out of the 45 women in which it had been tested since the assay's introduction in 1982

In the women with malignant disease clinicians diagnosed 34 tumours as benign and 47 as malignant. The general practitioners diagnosed 18 as malignant and 53 as benign; the diagnosis was not stated in 10 cases.

\section{CLINICALLY BENIGN}

Fine needle aspiration was performed in 27 patients (two did not have the procedure and five presented before the service was available). Malignancy was identified in $15(56 \%)$. In one woman insufficient tissue was obtained and in another the diagnosis was 